Via-Filling 공정시 발생하는 첨가제 분해에 관한 연구

이민형, 조진기

한국산업기술대학교, 신소재공학과

\title{
A study on the Additive Decomposition Generated during the Via-Filling Process
}

\author{
Min Hyeong Lee, Jin Ki Cho* \\ Department of Advanced Materials Engineering, Korea Polytechnic University, \\ Siheung 429-793, Korea
}

(Received August 19, 2013 ; revised August 25, 2013 ; accepted August 28, 2013)

\begin{abstract}
The defect like the void or seam is frequently generated in the PCB (Printed Circuit Board) Via-Filling plating inside via hole. The organic additives including the accelerating agent, inhibitor, leveler, and etc. are needed for the copper Via-Filling plating without this defect for the plating bath. However, the decomposition of the organic additive reduces the lifetime of the plating bath during the plating process, or it becomes the factor reducing the reliability of the Via-Filling. In this paper, the interaction of each organic additives and the decomposition of additive were discussed. As to the accelerating agent, the bis (3-sulfopropyl) disulfide (SPS) and leveler the Janus Green B (JGB) and inhibitor used the polyethlylene glycol 8000 (PEG). The research on the interaction of the organic additives and decomposition implemented in the galvanostat method. The additive decomposition time was confirmed in the plating process from $0 \mathrm{Ah} / l$ (AmpereHour/ liter) to $100 \mathrm{Ah} / l$ with the potential change.
\end{abstract}

Keywords: Via-Filling, PEG, SPS, JGB, $\mathrm{Cl}^{-}, \mathrm{PCB}$

\section{1. 서 론}

최근 스마트폰 등 전자기기의 성능 향상 및 소형 화로 인하여 요구되는 휴대성과 고기능성을 만족시 키기 위한 방법으로 PCB(Printed Circuit Board)의 다층화가 활발히 진행되고 있다 ${ }^{1,2,6)}$. 다층화의 진행 을 위하여 각 층간 전기적 연결법으로 $\mathrm{PCB}$ 비아 홀(via hole)을 전해 Via-Filling 도금을 하여 전기적 통로로 사용하는 방법이 중요시 되고 있다. $\mathrm{PCB}$ 비 아 홀은 신호의 유실 및 단락(Short)이 감소될 뿐만 아니라 부피를 감소시킬 수 있는 장점이 있다 ${ }^{2}$. 비 아 홀 내부는 전도성 물질을 충전하여야 하는데, 구 리 전해도금법은 비저항과 전기전도도가 우수하며

\footnotetext{
*Corresponding author. E-mail : chojk@kpu.ac.kr
}

공정비용이 저렴하여 양산에 용이하다 ${ }^{2)}$. 그러나 비 아 홀의 직경이 작아지고 종횡비가 증가함에 따라 전해도금시 비아 홀 내부에 기공(void)나 시임(seam) 등과 같은 결함이 발생되는 문제가 있다. 이러한 결 함은 회로의 전기적 특성을 떨어뜨리기 때문에 결 함없이 Via-Filling을 하는 연구가 요구된다 ${ }^{1}$. 결함 이 없는 구리도금을 위해서는 bottom-up 충전이 요 구되는데, bottom-up 충전시 억제제(suppressor) 역 할을 하는 $\mathrm{PEG}$ (polyethlylene glycol)와 가속제 (accelerator) 역할을 하는 황함유 유기화합물(sulfurcontaining organic compounds) 등을 이용하여 비아 홀의 입구 막힘 없이 바닥부터 충전이 이루어지도 록 하는 것이 중요하다 ${ }^{2)}$. 또한, Via-Filling 공정시 도금액 내에 전류가 가해지는데, 누적전류(Ah)에 의 해 첨가제의 특성이 약화되거나 달라져 도금액을 
수시로 교체해야 하는 번거로움도 문제가 되고 있 다 ${ }^{3,4}$. 이는 공정상의 비용을 증가시키며 Via-Filling 의 신뢰성을 떨어뜨리는 문제가 된다.

본 연구에서는 Via-Filling시 bottom-up 충전에 영 향을 주는 각 유기물 첨가제들의 특성 및 농도변화 에 따른 특성변화를 관찰하였으며, 누적 전류량에 따른 유기물 첨가제들의 특성변화를 통해 Via-Filling 에 미치는 누적전류의 영향을 확인하였다.

\section{2. 실험방법}

본 실험에서는 Via-Filling시 중요한 요건인 bottomup 충전을 위한 각 유기물 첨가제들의 영향을 알 아보기 위하여 첨가제의 농도에 따른 potential 변 화를 측정하였다. Via-Filling시 가속제를 첨가하면 potential이 증가하여 동일한 전류 인가시 potential 값 이 작은 때보다 양이온 $\left(\mathrm{Cu}^{+}\right)$의 석출을 가속시킨다 ${ }^{1)}$. 본 실험에서는 첨가제로 억제제인 PEG(polyethlylene glycol 8000), 가속제인 SPS(bis (3-sulfopropyl) disulfide), 평탄제(Leveler)인 JGB, 그리고 $\mathrm{PEG}$ 와 SPS의 음극표면으로의 흡착을 돕는 $\mathrm{Cl}^{-}$(염소이온) 을 사용하였다.

각 유기물 첨가제들의 bottom-up 특성 및 첨가제 농도변화에 따른 bottom-up 특성변화를 확인하기 위하여 황산 $\left(\mathrm{H}_{2} \mathrm{SO}_{4}\right)$ 과 $\mathrm{Cl}^{-}$의 농도를 각각 $70 \mathrm{ml} / \mathrm{l}$, $80 \mathrm{ppm}$ 으로 고정하고 황산구리 $\left(\mathrm{CuSO}_{4} \cdot 5 \mathrm{H}_{2} \mathrm{O}\right)$ 의 농 도를 $10 \mathrm{~g} / l$ 씩 변화시키면서 potential 변화를 측정 하였다. 이후 황산구리의 양을 potential 값이 가장 큰 농도로 고정하고 모든 첨가제를 포함한 도금욕 에 $\mathrm{PEG}, \mathrm{SPS}, \mathrm{JGB}$ 중 하나의 첨가량을 조정하여 potential 변화를 확인하였다. 측정은 정전류법 (Galvanostat method)으로 진행하였으며, 정전류법 측정시 전류(Current)는 $-100 \mathrm{~mA}$, 작업전극(Working electrode)으로는 $3 \times 3 \mathrm{~cm}^{2}$ 구리시편을 사용하였으 며, 상대전극(Counter electrode)으로는 $5 \times 10 \mathrm{~cm}^{2}$ 백 금, 기준전극(Reference electrode)으로는 칼로멜 전 극( $\mathrm{SCE}$, saturated calomel electrode)을 사용하였다. 정전류법 측정장비로는 ZAHNER사의 IM6를 사용 하였다.

또한, 각 유기물 첨가제에 전류가 가해져 누적 전 류량 $(\mathrm{Ah} / l)$ 이 증가함에 따른 유기물 첨가제들의 특 성변화를 알아보기 위하여, 기본 도금욕과 기본 도 금욕에 $\mathrm{PEG}, \mathrm{SPS}, \mathrm{JGB}$ 를 각각 첨가한 도금욕에서 Via-Filling 도금 공정과 같이 전해도금을 진행하면 서 누적 전류량이 일정 $\mathrm{Ah} / l($ AmpereHour/liter)가 되 었을 때 potential 변화를 측정하였다. 또한 ViaFilling한 시편을 단면분석(Cross-section)하여 각 유
기물 첨가제에 누적 전류량이 미치는 영향을 형상 적으로 확인하였다. Via-Filling 시편으로 $3 \times 3 \mathrm{~cm}^{2}$ CCL(copper clad laminates)에 9 개의 blind via를 $\mathrm{CNC}$ 드릴로 직경 $125 \mu \mathrm{m}$, 깊이 $135 \mu \mathrm{m}$ 으로 형성하 고, 씨앗층으로 무전해 동도금 및 전해 동도금을 내 부에 균일하게 $20 \mu \mathrm{m}$ 증착하였다. 이후 실험전 전 해 알칼리탈지를 1 분 20 초간 진행후, DI Water로 세척하고 황산 $10 \mathrm{wt} \%$ 수용액에서 20초간 침지하 여 산화막을 제거하고 DI Water로 세척후 전해도 금을 실시하였다. Via-Filling 도금은 상온에서진행 하였고 전류밀도는 $1.5 \mathrm{~A} / \mathrm{dm}^{2}$ 이며 1시간 30 분 동안 도금하였다.

\section{3. 결과 및 고찰}

\section{1 첨가제 농도에 따른 Potential 변화}

그림 1 에서 황산구리 농도가 $10 \mathrm{~g} / l$ 씩 증가할수록 potential이 증가하면서 도금의 가속효과를 보였다. 황산구리 농도가 $170 \mathrm{~g} / l$ 이상일 경우에는 potential 이 일정하게 유지되었다. 이후 실험에서는 구리의 양을 $170 \mathrm{~g} / /$ 로 고정하여 진행하였다.

$\mathrm{PEG}$ 는 그림 2에서 보이는 것과 같이 첨가량을 $100 \mathrm{ppm}$ 씩 증가시키다 $800 \mathrm{ppm}$ 일 때 potential이 급 격히 감소하여 최소치를 나타내었으며, 이후 첨가 량이 더 증가할 때에는 potential이 증가하는 경향 을 보였다. Potential 측정으로 $\mathrm{PEG}$ 의 첨가량이 $800 \mathrm{ppm}$ 일 때 bottom-up 충전에서 억제효과가 가장 두드러지는 것을 확인하였다. $\mathrm{PEG}$ 는 특정 첨가량 에서 억제효과가 두드러지는데, $\mathrm{PEG}$ 는 $\mathrm{Cl}^{-}$과 결합 하여 $\mathrm{PEG}-\mathrm{Cl}$ 로 음극에 흡착하여 도금을 억제하는 것으로 알려져 있다).

$\mathrm{SPS}$ 는 그림 3 에서 보이는 것과 같이 첨가량을 $1 \mathrm{ppm}$ 씩 증가시켰을 때 첨가량이 증가할수록 potential

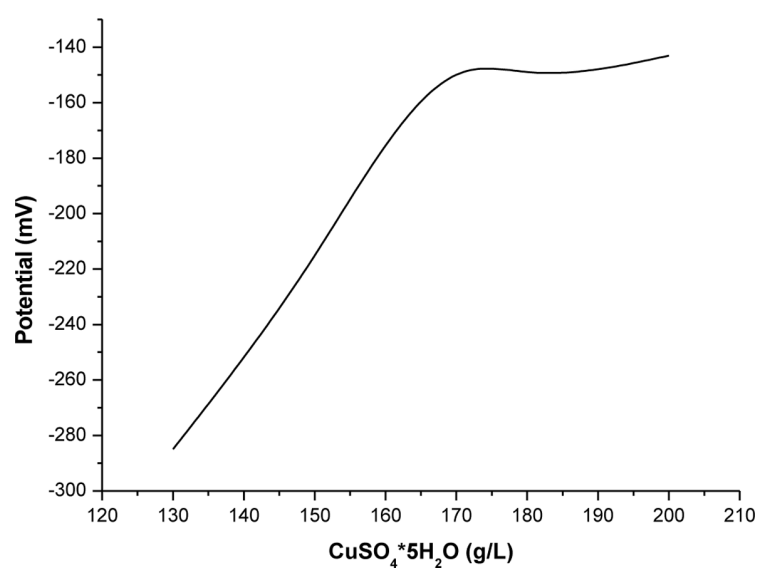

Fig. 1. The potential variation according to the $\mathrm{CuSO}_{4}$ . $5 \mathrm{H}_{2} \mathrm{O}$ concentration. 


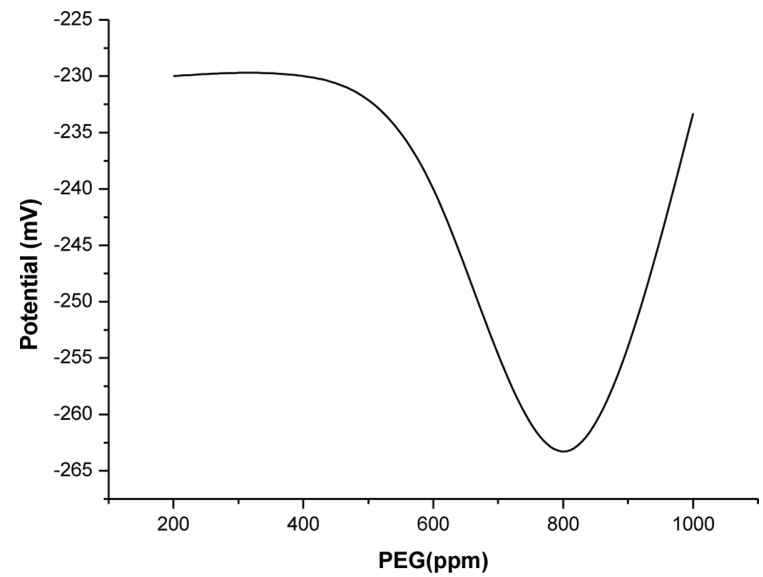

Fig. 2. The potential variation according to PEG additive concentration.

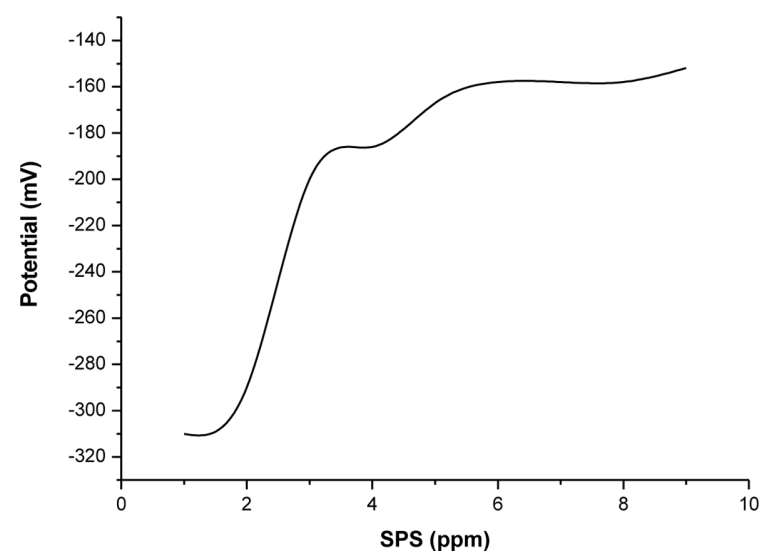

Fig. 3. The potential variation according to SPS additive concentration.

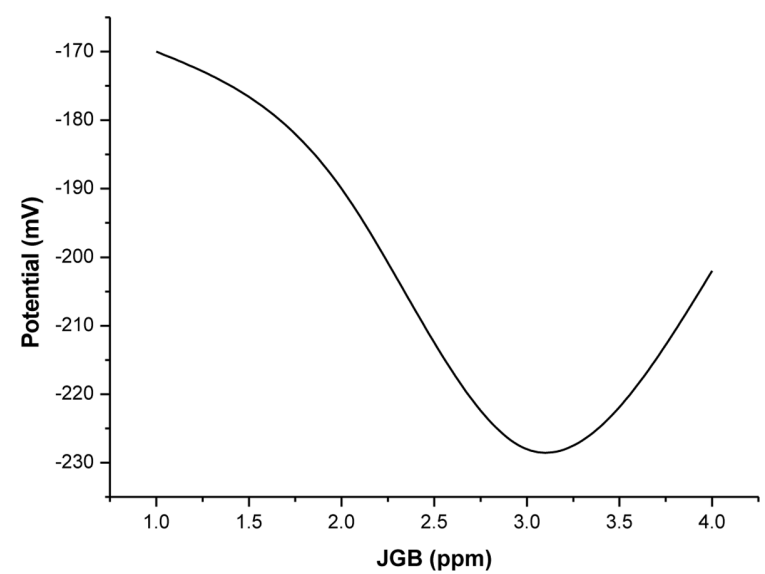

Fig. 4. The potential variation according to JGB additive concentration.

이 증가하며, potential 측정으로 SPS의 가속효과를 확인하였다. $\mathrm{JGB}$ 는 그림 4 에서 보이는 것과 같이 첨가량을 $0.5 \mathrm{ppm}$ 씩 증가시켰을 때 첨가량이 증가 할수록 potential이 감소하였으며, 첨가량이 $3 \mathrm{ppm}$ 일 때 bottom-up 충전에서 $\mathrm{JGB}$ 의 특성인 억제효과
가 가장 두드러지는 것을 확인하였다.

\section{2 누적 전류량(Ah)에 따른 Potential 변화}

누적 전류량에 따른 potential 변화를 알아보기 위 한 실험의 기본 도금욕과 기본 도금욕에 각각의 첨 가제 한 종류씩을 첨가한 도금욕의 조성은 표 1 과 같다.

누적 전류량에 따른 potential 변화를 알아보기 위 한 실험은 전해도금시 전류의 흐름에 따라 구리가 석출되어 도금욕의 구리 양이 점점 감소하기 때문 에, potential은 구리가 도금욕 내에 존재하지 않는 적정수준까지 감소하게 되어 Ah-Potential graph는 전체적으로 '乙' 자형을 그리게 된다.

기본 도금욕(Bath)과 기본 도금욕에 $\mathrm{PEG}$ 를 첨가 한 도금욕(PEG)의 누적 전류량 증가에 따른 potential 변화는 그림 5 에 나타내었다. PEG 도금욕은 누적 전류량이 $50 \mathrm{Ah} /$ 까지 potential이 크게 감소하다 이 후부터는 서서히 증가하였다. PEG는 bottom-up 특 성에서 억제효과를 갖는데, 누적 전류량이 $50 \mathrm{Ah} / l$ 이상일 경우 potential이 증가한다는 것은 억제효과 가 감소한다는 의미를 가지며, 이는 PEG의 bottom-

Table 1. Basic plating bath compositon and amount of organic additives

\begin{tabular}{|c|c|}
\hline \multicolumn{2}{|c|}{ Basic plating bath compositon (/L) } \\
\hline $\mathrm{CuSO}_{4} \cdot 5 \mathrm{H}_{2} \mathrm{O}$ & $170 \mathrm{~g}$ \\
\hline $\mathrm{H}_{2} \mathrm{SO}_{4}$ & $70 \mathrm{ml}$ \\
\hline $\mathrm{Cl}^{-}$ & $80 \mathrm{ppm}$ \\
\hline Amount of organic additives \\
\hline PEG & $800 \mathrm{ppm}$ \\
\hline SPS & $9 \mathrm{ppm}$ \\
\hline JGB & $3 \mathrm{ppm}$ \\
\hline
\end{tabular}

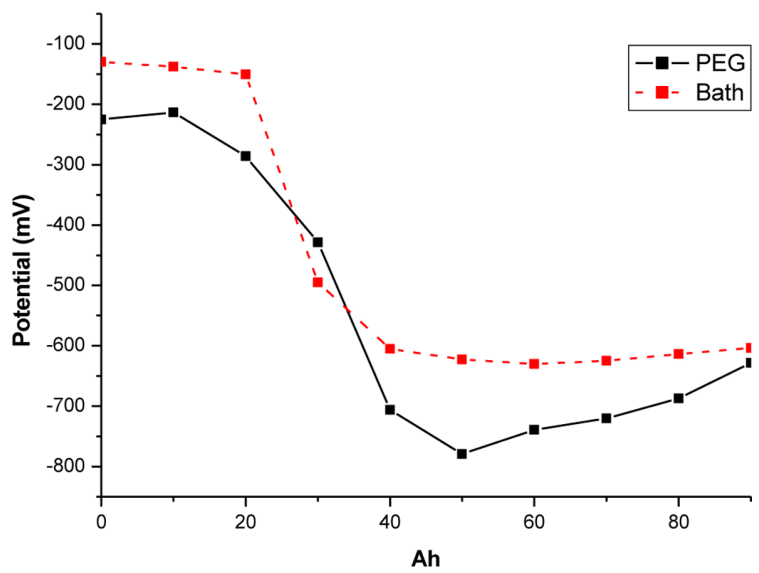

Fig. 5. The potential variation according to the accumulated current amount of the basic plating bath and PEG plating bath. 
up 특성이 저하됨을 뜻한다. 따라서 $\mathrm{PEG}$ 는 전류에 의해 분해가 되며 ${ }^{3)}$, potential이 서서히 증가하는 것 으로 보아 $\mathrm{PEG}$ 의 분해는 일정 누적 전류량 이상에 서 가해지는 전류에 의해 서서히 분해됨을 확인하 였다.

기본 도금욕(Bath)과 기본 도금욕에 SPS를 첨가 한 도금욕(SPS)의 누적 전류량 증가에 따른 potential 변화는 그림 6에 나타내었다. SPS 도금욕은 누적 전류량이 $40 \mathrm{Ah} / l$ 이상이 되었을 때부터 potential이 감소하여 $70 \mathrm{Ah} / l$ 가 누적되었을 시에 가장 최소치 를 나타낸다. SPS는 bottom-up 특성에서 가속효과 를 갖는데 누적 전류량이 $40 \mathrm{Ah} / l$ 이상일 경우 potential이 감소한다는 것은 가속효과가 감소한다 는 의미를 가지며, 이는 SPS의 특성이 저하됨을 뜻 한다. 또한 40 70 Ah/l 구간에서 지속적으로 potential 이 감소하는 것으로 보아 SPS의 분해는 일정 누적 전류량 이상에서 가해지는 전류에 의해 서서히 분 해됨을 확인하였다.

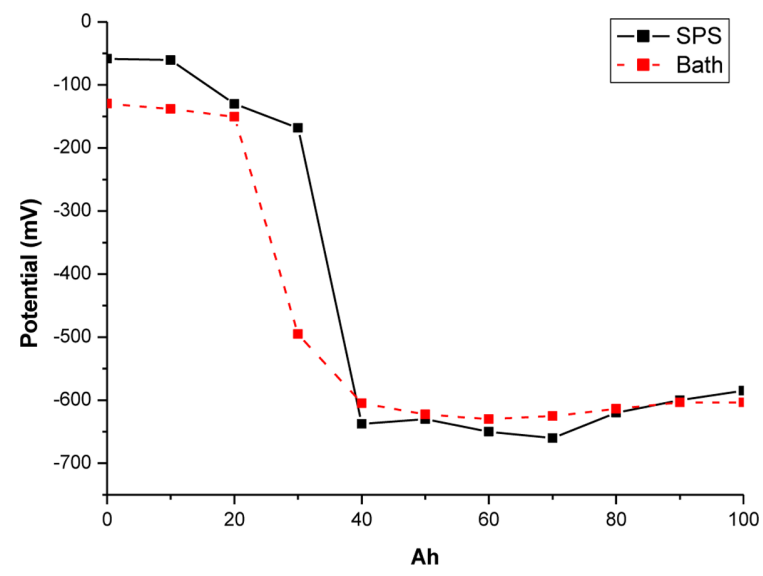

Fig. 6. The potential variation according to the accumulated current amount of the basic plating bath and SPS plating bath.

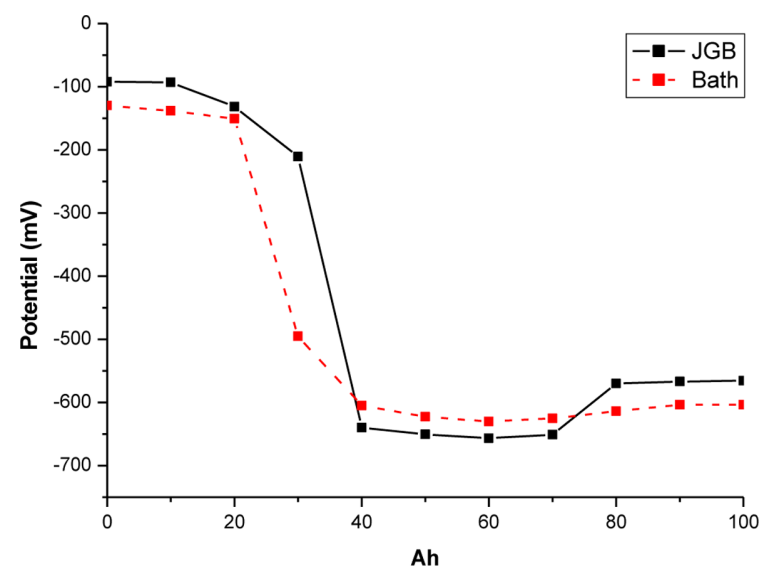

Fig. 7. The potential variation according to the accumulated current amount of the basic plating bath and JGB plating bath.
기본 도금욕(Bath)과 기본 도금욕에 $\mathrm{JGB}$ 를 첨가 한 도금욕(JGB)의 누적 전류량 증가에 따른 potential 변화는 그림 7에 나타내었다. JGB 도금욕은 누적 전류량이 $70 \mathrm{Ah} / l$ 가 되었을 때까지는 bottom-up에서 $\mathrm{JGB}$ 의 특성인 억제효과를 나타내는 potential 값을 나타내나, $70 \mathrm{Ah} / l$ 이상의 누적 전류량이 누적되었 을 때에 바로 potential은 증가한다. 이는 $\mathrm{JGB}$ 의 bottom-up 특성이 저하됨을 뜻한다. 또한, 누적 전 류량이 $70 \mathrm{Ah} / l$ 이하일 때 potential 값은 억제효과 의 값으로 일정하게 나타나지만, 누적 전류량이 $70 \mathrm{Ah} / l$ 이상일 때 potential이 바로 증가하는 것으 로 보아 $\mathrm{JGB}$ 의 분해는 일정 누적 전류량 이상의 전류가 가해졌을 시 크게 분해됨을 확인하였다.

\section{3 첨가제 분해에 따른 Via-Filling 차이}

그림 8은 PEG 도금욕에서 Via-Filling한 시편의 단면으로, 누적 전류량 $0 \mathrm{Ah} / /$ 에서 Via-Filling한 시 편은 bottom-up 충전이 되었다. 또한 비아 홀 옆의 평면 도금두께는 $57 \mu \mathrm{m}$ 이었다 (그림 8(a)). 그러나 누적 전류량 $90 \mathrm{Ah} /$ 에서 Via-Filling한 시편은 비아 홀 내부에 전체적으로 도금이 되었으며, 평면 도금 두께는 $81 \mu \mathrm{m}$ 으로 두꺼웠다(그림 8(b)). 이는 억제 제인 $\mathrm{PEG}$ 가 억제효과를 갖지 못하여 홀 내부에 전 반적인 도금이 진행되었으며, 또한 평면의 도금두 께가 두꺼워졌다. 이러한 경향은 $\mathrm{PEG}$ 가 전류에 의 해 분해가 되었으며, 그로 인하여 $\mathrm{PEG}$ 의 억제효과

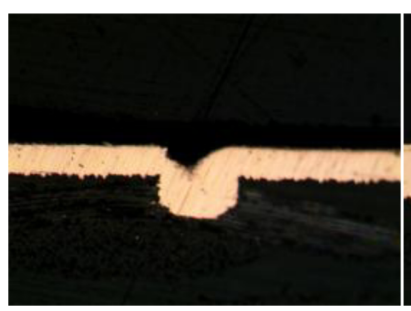

(a)

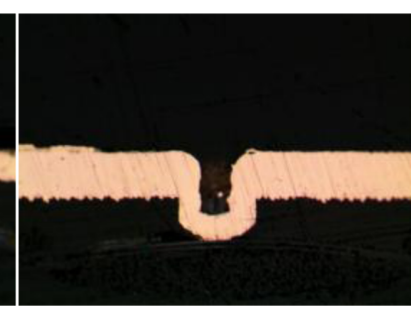

(b)
Fig. 8. The Via-Filling specimen cross-section according to the accumulation current amount difference of PEG plating bath. (a) $0 \mathrm{Ah} / /$ (b) $90 \mathrm{Ah} / \mathrm{I}$

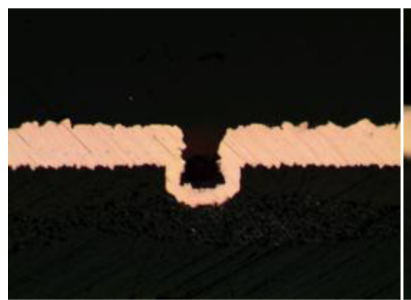

(a)

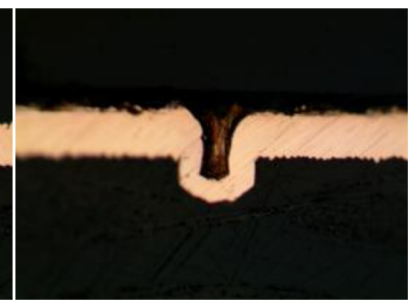

(b)
Fig. 9. The Via-Filling specimen cross-section according to the accumulation current amount difference of SPS plating bath. (a) $0 \mathrm{Ah} / \mathrm{l}$ (b) $70 \mathrm{Ah} / \mathrm{l}$ 
가 저하되었음을 나타낸다.

그림 9는 SPS 도금욕에서 Via-Filling한 시편의 단 면으로, $0 \mathrm{Ah} / /$ 에서 Via-Filling한 시편은 평면 및 비 아 홀 내부에 도금이 불균일한 형태로 되었지만(그 림 9(a)), $70 \mathrm{Ah} /$ 에서 Via-Filling한 시편은 평면 및 비아 홀 내부에 도금이 균일한 형태로 되었다(그림 9(b)). 이는 가속제인 SPS의 특성인 가속효과에 의 해 $0 \mathrm{Ah} / /$ 에서는 도금이 촉진되어 구리이온이 불균 일하게 석출되었지만, $70 \mathrm{Ah} / l$ 에서는 SPS의 특성인 가속효과가 약화되어 균일하게 도금이 되었다 ${ }^{5}$. 이 러한 경향은 SPS가 전류에 의해 분해가 되어 가속 효과가 저하되었음을 나타낸다.

그림 10은 JGB 도금욕에서 Via-Filling한 시편의 단면으로, $0 \mathrm{Ah} / l$ 에서 Via-Filling한 시편은 비아 홀 내부에 도금층이 형성되었으며, 평면도금두께는 $76 \mu \mathrm{m}$ 이었다(그림 10(a)). 그러나 $80 \mathrm{Ah} / /$ 에서 ViaFilling한 시편은 비아 홀 내부에 도금층이 적게 형 성되었으며, 평면 도금두께는 $97 \mu \mathrm{m}$ 이었다(그림 10(b)). $0 \mathrm{Ah} /$ /에서 Via-Filling한 시편은 레벨러의 평 탄효과로 인하여 내부에 불균일한 부분에서 평탄하 게 만드는 내부 도금층이 형성되었고, 레벨러가 갖 는 억제효과로 인하여 평면 도금두께 또한 얇다. 그 러나 $80 \mathrm{Ah} / /$ 에서 Via-Filling한 시편은 레벨러의 평 탄효과 약화로 인하여 내부 도금층이 매우 적게 형 성되었으며, 억제효과의 약화로 인하여 평면의 도 금두께 또한 두꺼워졌다. 이것은 JGB가 전류에 의

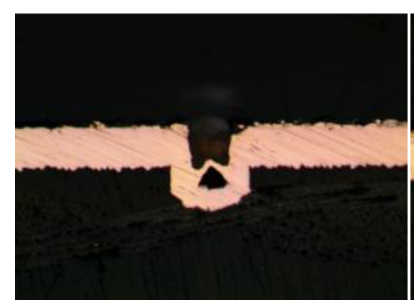

(a)

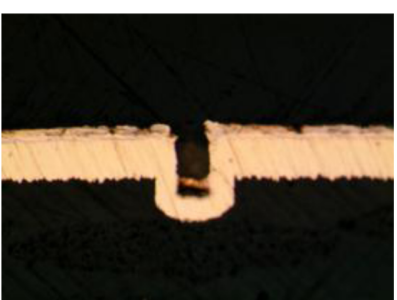

(b)
Fig. 10. The Via-Filling specimen cross-section according to the accumulation current amount difference of JGB plating bath. (a) $0 \mathrm{Ah} / /$ (b) $80 \mathrm{Ah} / \mathrm{l}$.

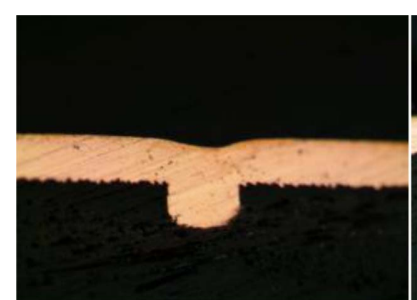

(a)

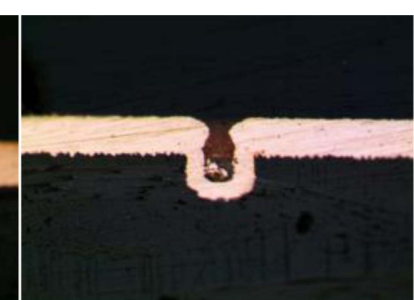

(b)
Fig. 11. The Via-Filling specimen cross-section according to the accumulation current amount difference of Via-Filling bath. (a) $0 \mathrm{Ah} / \mathrm{l}$ (b) $80 \mathrm{Ah} / \mathrm{l}$.
해 분해가 되었으며, 그로 인하여 $\mathrm{JGB}$ 의 평탄효과 및 억제효과가 약화되었음을 나타낸다.

그림 11 은 유기물 첨가제를 모두 포함한 도금욕 에서 Via-Filling한 시편의 단면으로, $0 \mathrm{Ah} /$ 에서 ViaFilling한 시편은 기공이나 시임이 나타나지 않은 bottom-up 충전이 이루어졌다(그림 11(a)). $80 \mathrm{Ah} / l$ 에서 Via-Filling한 시편은 비아 홀 입구쪽 도금이 촉진되는 현상을 보였으며, Via-Filling이 되지 않았 다(그림 $11(\mathrm{~b})$ ). Via-Filling시 각 첨가제의 작용으로 인한 bottom-up 충전이 되어야 하는데, $0 \mathrm{Ah} / l$ 에서 는 각 첨가제들이 bottom-up 충전에 영향을 미쳐서 $100 \%$ 충전이 되었다. 그러나 누적 전류량이 $80 \mathrm{Ah} /$ $l$ 인 도금욕에서는 각 유기물 첨가제들의 영향이 약 화되어 Via-Filling이 되지 않았다.

\section{4. 결 론}

Via-Filling시 각 첨가제들의 bottom-up 충전 특성 인 $\mathrm{PEG}$ 의 억제, $\mathrm{SPS}$ 의 가속, $\mathrm{JGB}$ 의 억제효과를 정 전류법을 통하여 potential로 확인하였다. PEG와 $\mathrm{JGB}$ 는 일정 첨가량에서 억제효과가 두드러지게 나 타나며, 일정농도 이상에서는 효과가 감소하였다. $\mathrm{SPS}$ 는 첨가제 농도 증가에 따라 potential이 증가 했다.

누적 전류량(Ah)에 따른 potential 변화측정 실험 에서 각 첨가제는 일정 누적 전류량 이상에서 분해 가 시작되며, 분해 후 첨가제의 bottom-up 특성이 저하됨을 확인하였다. 또한, $\mathrm{PEG}$ 는 일정 누적 전류 량 이상에서 분해가 시작되며, $\mathrm{SPS}$ 와 $\mathrm{JGB}$ 에 비하 여 서서히 분해되는 것을 확인하였다. 이러한 결과 를 첨가제 분해 전 후의 도금욕에서 Via-Filling하 여 단면관찰로 bottom-up 특성이 저하되는 것을 형 상적으로 확인하였다.

\section{References}

1. S.-E. Lee, J.-H. Lee, Electrochem. Soc., 14 (2007) 3.

2. S. C. Hong, D. H. Jung, J. P. Jung, W. Kim, J. Kor, Inst, Met \& Mater., 50 (2011) 2.

3. Y.-B. Li, W. Wang, Y.-L. Li, Appl. Surf. Sci., 255 (2009) 3977.

4. W. Wang, Y.-B. Li, Y.-L. Li, Appl. Surf. Sci., 255 (2009) 4389.

5. J.-Y. Lee, M. Kim, K. H. Lee, S.-B. Yim, J. I. Lee, J. Kor. Inst. Surf. Eng., 43 (2010) 1.

6. W.-P. Dow, M.-Y. Yen, C.-W. Liu, C.-C. Huang, Electrochimica Acta, 53 (2008) 3610. 